\title{
La imaginación ecológica en el cómic español
}

\section{Ecological Imagination in Spanish Comics}

\author{
Jorge Catalá \\ Newcastle University \\ Christine M. Martínez
}

New York University

Jorge Catalá-Carrasco es Senior Lecturer in Hispanic Studies en la Newcastle University (Reino Unido). Se doctoró en la University of Nottingham en 2010 con una tesis que publicó en 2015 con el título Vanguardia y Humorismo Gráfico en Crisis: La Guerra Civil Española (1936-1939) y la Revolución Cubana (1959-1961) (Tamesis). $\mathrm{Su}$ área de investigación son los estudios culturales, la cultura popular y la historia cultural en periodos de crisis, con un enfoque en el cómic en España y Latinoamérica. Es autor de cuatro libros editados en co-autoría (entre ellos, Comics and Memory in Latin America, 2017, que también fue publicado en español por Cátedra en 2019) y ha coordinado dos números especiales para revistas académicas.

Christine M. Martínez es doctora en literatura y estudios culturales ibéricos por la Universidad de Nueva York (NYU) (2021). Actualmente, es docente y becaria posdoctoral en el programa de educación general y las humanidades de NYU. Sus investigaciones se centran en el estudio de las causas culturales y raíces coloniales de la emergencia socioambiental actual, con un enfoque en la cultura visual y la ecología política de la España democrática y sus periferias. Está particularmente interesada en estudiar la obra y las ideas de grupos y comunidades que proponen alternativas a los valores y las prácticas insostenibles del capitalismo contemporáneo. Ha publicado varios artículos y capítulos de libro sobre el cómic español y la crítica socioecológica de la sociedad de consumo.

Fecha de recepción: 29 de octubre de 2021

Fecha de aceptación definitiva: 2 de diciembre de 2021 


\title{
Resumen
}

En este ensayo, señalamos la gran diversidad de obras en la historia del cómic español que se preocupan por temas ecológicos, establecen alianzas con movimientos ecologistas, y que desarrollan una crítica ecológica del capitalismo contemporáneo y la cultura de consumo. Abogamos por el estudio ecocrítico del cómic de cualquier temática (un enfoque relativamente ausente en el campo) y por el empleo del cómic para una concienciación ecológica fundamentalmente crítica de las estructuras de poder y el metabolismo del capitalismo globalizado y para el desarrollo de formas «ecológicas» de representar la actualidad.

Palabras clave: cómic español, crisis ecológica, ecocrítica, historia del cómic

\begin{abstract}
In this essay, we highlight the significant diversity of works in the history of Spanish comics that engage ecological concern, alliances with environmentalist movements, and ecological critiques of contemporary capitalism and consumer society. We signal the need for more ecocritical studies of comics of all topics and highlight the potential of comics for promoting an ecological awareness that is fundamentally critical of the power structures and metabolism of global capitalism and for developing «ecological» modes of storytelling.
\end{abstract}

Keywords: comics history, ecocriticism, ecological crisis, Spanish comics

\section{Cita bibliográfica}

Catalá, J. y Martínez, C. M. «La imaginación ecológica en el cómic español», en CuCo, Cuadernos de cómic, n. 17 (2021), pp. 18-37. 


\section{Introducción}

En las últimas décadas, hemos presenciado una mayor concienciación sobre las consecuencias devastadoras del metabolismo acelerado del capitalismo contemporáneo en los países históricamente privilegiados por el sistema económico dominante, algo ya de sobra conocido por las comunidades y regiones marginalizadas por este sistema. La creciente preocupación por las consecuencias socioambientales de la economía dominante en el Norte global y entre las clases urbanas, por ejemplo, se debe en gran parte a la exacerbación y proliferación de una serie de crisis socioecológicas a nivel planetario. Los impactos de estas crisis desbordan fronteras y hacen cada vez más difícil la perpetua externalización de las consecuencias necróticas del desarrollo capitalista hacia regiones y comunidades desfavorecidas o generaciones futuras. ${ }^{1}$

En este contexto, no sorprende que exista un número cada vez mayor de autores de cómic que utilicen su arte - un arte cuyos orígenes radican en la cultura urbana y de consumo de masas - para la representación de las actuales crisis. Recientemente, periodistas y dibujantes como Philippe Squarzoni (Saison Brune, 2012), Susie Cagle (reportajes publicados en el diario inglés The Guardian) y Nick Sousanis con Richard Monastersky («The Fragile Framework», Nature, 2015), han narrado las dimensiones científicas y políticas del cambio climático desarrollando una metodología propia a través del periodismo gráfico. Con un enfoque conceptualmente cercano, encontramos otras obras que han representado el impacto catastrófico de las grandes corporaciones e industrias extractivas sobre comunidades autóctonas - por ejemplo, el webcómic peruano de 2017 La guerra por el agua del artista Jesús Cossio, la periodista Luna Amancio y el programador Jason Martínez, y el libro Paying the Land de Joe Sacco en 2020 - o que han demostrado el impacto desigual de las catástrofes climáticas sobre las comunidades empobrecidas y marginalizadas — por ejemplo, A.D. New Orleans After the Deluge, publicado en 2009 por Josh Neufeld, y Puerto Rico Strong, la antología de cómics publicada en 2018 de manera conjunta por Fondos Unidos de Puerto Rico y Lion Forge.

En España el cómic atraviesa un periodo extraordinario por la calidad de las obras publicadas, la extensa nómina de autores de varias generaciones que siguen en activo y la gradual normalización de la historieta en el panorama cultural español. Por tanto, no debería sorprender que se haya producido un incremento importante en las obras gráficas que tratan explícitamente los temas ecológicos, las crisis socioecológicas y la

${ }^{1}$ Entre las crisis socioambientales planetarias más preocupantes para el ser humano están el calentamiento global; la extinción masiva de especies y la pérdida de biodiversidad; la degradación de ecosistemas; las migraciones masivas provocadas por sequías, inundaciones y la subida del nivel de mar; la acidificación oceánica y la acumulación de plásticos y otros residuos tóxicos. 
ecología política de la sociedad de consumo y de ciertas industrias con gran peso en el capitalismo español contemporáneo, como el turismo y la construcción. En 2015, Jorge Carrión y Sagar Forniés publicaron el cómic periodístico Barcelona: Los vagabundos de la chatarra, que traza el metabolismo social, económico y ecológico de los desechos en Barcelona durante los años de la crisis económica. Otro ejemplo reciente es el cómic de ficción de Ana Penyas Todo bajo el sol (2021) que narra, con un enfoque coral, la gentrificación urbana y la transformación de la costa levantina por el turismo desenfrenado. Un ejemplo colaborativo entre artistas y ONGs para la concienciación climática es la iniciativa de la ONG española CESAL, Puro Perú (2019), en la que participan varios dibujantes españoles.

Otros artistas demuestran un interés por temas ambientales de más largo aliento como, por ejemplo, la historieta de tema ambientalista de Ramón Hipo, Popo, Pota, y Tamo, publicada en el periódico El País (2006-2014). De hecho, la incorporación de Ramón como humorista gráfico a la nómina de autores de El País en febrero de 2006 y la creación de la revista mensual Tierra en 2007 reflejaron y favorecieron una mayor sensibilidad hacia temáticas medioambientales como evidencia una revisión de la hemeroteca de El País durante los meses de enero a julio de 2006. En enero, los ejemplos sobre explotación urbanística son frecuentes (5/01/06 Romeu; 19/01/06 Máximo; 24/01/06 El Roto) hasta el punto de que El Roto (pseudónimo de Andrés Rábago) se pregunta (23/01/06) sobre el tipo de sociedad a la que se encaminaba España y la necesidad de proteger huertos vecinales entre un mar de ladrillo, ejemplo que ya nos sitúa dentro de una temática medioambiental. Pero ya para abril se aprecia un mayor interés sobre la sobreexplotación del litoral y la corrupción (04/04/06 y 11/04/06 Forges; 08/04/06 Máximo; 09/04/06 Romeu; 19/04/06 El Roto), hasta dejar un regusto amargo en la felicitación del día de La Tierra reflejada por Forges $(22 / 04 / 06)$. De entre los artistas gráficos que se han preocupado por una temática ecológica fundamentalmente crítica del capitalismo contemporáneo globalizado y la cultura de consumo de masas destacan los libros de Miguel Brieva (Memorias de la tierra, 2012) y El Roto (El libro verde, 2014) que recopilan viñetas publicadas anteriormente en El Pais (E1 Roto) o en Tierra (publicada por El Pais entre 2007 y 2011) (Brieva).

Hasta el momento se han publicado pocos estudios sobre temática ecológica o ambientalista y la crítica ecológica del capitalismo en el cómic, y menos aún son los que analizan cómo el formato específico del cómic se presta para la representación «ecológica» (i.e. la representación de relaciones entre múltiples actores, temporalidades y subjetividades) o que desarrollen perspectivas «ecocríticas» de la sociedad contemporánea. La hispanista Tania Pérez Cano incluyó un capítulo sobre las «ecosecuencialidades» del cómic español y latinoamericano en su monográfico Imposibilidad del beatus ille, publicado en 2016. En 2020 se publicó EcoComix: Essays on the Environment in Comics and Graphic Novels, editado por Dobrin, especialista en estudios sobre escritura. El monográfico contextualiza la larga trayectoria 
de representación ambientalista en el cómic de tradición anglo-americana, pero las firmas participantes tienen un enfoque no solo ecocrítico sino también ecofeminista, queer, posthumano, semiótico y desde los estudios animales. Asimismo, Closure, una revista alemana de cómics, publicó en 2020 una edición especial sobre los «eco-comics» («What Grows in the Gutter? Eco-Comics», vol. 7), editada por Cord-Christian Casper. También la ahora difunta Adele Haverty-Bealer publicó en 2017 una tesis innovadora en el campo de estudio ecocrítico del cómic. No obstante, estos estudios son escasos (y nuestro listado es necesariamente incompleto) si se toma en cuenta: (1) la cantidad sustancial de cómics que, ya desde los primeros movimientos ecologistas, han representado temas ambientales; (2) la profundidad con la que los cambios ecológicos están transformando el terreno político del siglo xxı; y (3) la riqueza de estudios ecocríticos elaborados en los últimos treinta años sobre el cine, la literatura, el arte plástico y otros campos de la producción cultural. $^{2}$

Este ensayo busca animar el estudio ecocrítico del cómic español, no solo en aquellas obras de temática abiertamente ambientalista sino también —y más aún — anima a analizar cómo se ha percibido, definido, fragmentado, y enmarcado el medio ambiente, la cultura humana y la vida no humana en el cómic de cualquier temática. Del mismo modo animamos el estudio de cómo se han visibilizado o reproducido los puntos ciegos de la sociedad de consumo en el cómic en general. Por puntos ciegos nos referimos, por ejemplo, a los desechos generados por el consumo de bienes y energía, además de los ecosistemas, comunidades y formas de vida sostenibles sacrificados en el saqueo de materias primas y fuentes energéticas por políticas extractivistas. Para ello, proponemos algunas pistas y un marco histórico que esboza períodos de particular interés en la trayectoria del imaginario ecológico del cómic español desde los primeros acercamientos fruto de la alianza con movimientos ambientalistas, contraculturales y anarquistas de la década de 1970, hasta un momento más reciente que

${ }^{2}$ Otros estudios que analizan el uso del cómic para fines ecologistas o para desarrollar críticas ecológicas del capitalismo contemporáneo incluyen el capítulo de Vold, V. en el monográfico Ecomedia (coordinado por Rust et al.,2015) sobre la estética de la justicia ambiental en historietas estadounidenses; el estudio de Saltzman, M. sobre la ecología urbana de los desechos y el cómic Barcelona: los vagabundos de la chatarra en su libro de pronta aparición titulado Everyday Agency in the Discarded; el capítulo de Almanza-Gálvez, C. «La cuenta atrás: An Ecodystopian Graphic Novel on Spain's Greatest Ecological Disaster», en Leone, M. y Lino, S. Beyond Human: Decentering the Anthropocene in Spanish Ecocriticism (un libro de pronta aparición), que analiza la representación del catastrófico derrame de petróleo en el cómic de Portela y San Julián La cuenta atrás (2008); las publicaciones de Martínez, C. sobre las propuestas del decrecimiento en la obra de Miguel Brieva (2017); el uso del cómic periodístico para representar las ecologías urbanas en Barcelona: los vagabundos de la chatarra (2019); el empleo de la sátira y el antropomorfismo para la concienciación ambiental en los cómics de Brieva, El Roto y Ramón (el mismo libro de pronta aparición coordinado por Leone y Lino); y la importancia de la política intergeneracional de la obra de Ana Penyas para la imaginación sostenible (2021). Barcelona también ha sido fruto de análisis en un artículo de CATALÁ, J. (2017) a través de una crítica a la racionalidad neoliberal y las políticas extractivas en el entorno urbano. Finalmente, Prádanos, L. I. tiene un artículo de pronta aparición en la revista Hispanófila sobre la ecología del turismo en la novela gráfica de Penyas Todo bajo el sol. 
Luis I. Prádanos ha denominado como «los imaginarios del postdesarrollo». ${ }^{3}$ Nos enfocamos en la tradición española del cómic por la profusión de dibujantes que han representado preocupaciones ambientalistas y por la relativa falta de estudios que analicen sus obras. El artículo concluye con un breve resumen de algunas tácticas empleadas por varios dibujantes para fomentar imaginarios «ecológicos» de pensamiento y narración. Estas tácticas incluyen, por ejemplo, modos de representación que enfatizan la presencia y las interconexiones de múltiples actores, seres, y fenómenos que son con frecuencia obviados convenientemente en las narraciones antropocéntricas y consumistas del capitalismo tardío.

\section{Marco teórico}

La ecocrítica se refiere al estudio de la relación entre la literatura y el ambiente físico. ${ }^{4}$ En este sentido, se puede desarrollar un estudio ecocrítico de textos y narrativas de cualquier temática ya que cada texto implica ciertos modos de ver que construyen este ambiente físico y participa de prácticas de elaboración y difusión que tienen impactos físicos - por ejemplo, la impresión y el consumo de cómics o el gasto energético necesario para almacenar y leerlos digitalmente-. Empleando el prefijo «eco-» para indicar la relacionalidad, un aspecto central de cualquier ecosistema, Dobrin y Weisser describen la «ecocomposición»: un modo de investigación y teorización que estudia las relaciones que hacen posible y dan sentido a la producción literaria como preguntarse por las comunidades humanas y no humanas y por tradiciones de pensamiento filtradas por la voz narrativa-.${ }^{5}$ Este uso del prefijo «eco-» contrasta con usos populares, vistos, por ejemplo, en discursos mediáticos y en campañas de mercadotecnia que emplean el prefijo como abreviatura del concepto (vago y vacío) environmentally-friendly o como sinónimo del significante (igualmente vago y vacío) «verde».

Cualquier texto narra o implica cierta ecología de relaciones y es importante destacar que estas ecologías son siempre representaciones incompletas definidas por una serie de limitaciones, políticas y prioridades. Lo importante para la ecocrítica es preguntarse por estas limitaciones, políticas y prioridades, considerando la relación entre las representaciones o puntos ciegos de una determinada obra artística o literaria y las prácticas culturales que afectan a la biosfera y las comunidades humanas y no humanas

\footnotetext{
3 Prádanos, L. I. Postgrowth Imaginaries. New Ecologies and Counterhegemonic Culture in Post-2008 Spain. Liverpool, Liverpool U. P., 2018.

${ }^{4}$ Glotfelty, C. «Introduction», en Glotfelty, C. y Fromm, H. (eds.). The Ecocriticism Reader: Landmarks in Literary Ecology, Georgia, Georgia U. P., 1996, p. xviii.

5 Trevathan, J. en referencia a la teoría «actor-network» de lectura de Rita Felski («Context Stinks»! New Literary History, 14 (4), 573-91), describe además cómo el significado de un texto cambia según su contexto, i. e., el lugar en que se lee («Coda 2: The Trees Are Not What They Seem». Arizona Journal of Hispanic Cultural Studies, n. ${ }^{\circ} 23,2019$, pp. 253-258).
} 
más vulnerables a largo plazo. En los textos que reflejan las prioridades antropocéntricas del capitalismo tardío, suelen pasar desapercibidos los actores, las comunidades y las escalas de tiempo que complican la euforia del discurso dominante del crecimiento económico — por ejemplo, los seres no humanos, las generaciones futuras, vertederos, comunidades periféricas-. Katarzyna Beilin analiza los «puntos ciegos» de la cultura financiarizada del capitalismo tardío como un elemento importante en el mantenimiento de jerarquías económicas existentes y prácticas culturales ecológicamente y socialmente dañinas - como el impacto ecológico del consumo de carne o el uso de plásticos de un solo uso-. Del mismo modo, Samuel Amago describe cómo los sistemas creados para gestionar la basura de las ciudades modernas minimizan la posibilidad de cualquier toma de conciencia significativa con el despilfarro excesivo producido por el sistema económico actual. ${ }^{6}$ Como apuntan Lindner y Meissner, la circulación global de desechos determina por un lado la acumulación de capital extrayendo de la basura materias primas que generan un beneficio- pero también la redistribución de riesgos, por lo que cuestiones como el dónde, el cómo y con qué propósito fluye la basura son fundamentales. ${ }^{7}$ En una línea también transnacional, Sassen ha denunciado que los programas de reestructuración de deuda soberana en el Sur Global durante las décadas de 1980 y 1990 tenían como objetivo transformar sus economías y convertir los países en lugares propicios para las prácticas extractivas de recursos naturales valiosos. ${ }^{8} Y$ desde una crítica al consumismo desmesurado, Prádanos también critica las infraestructuras urbanas y las narrativas que promueven el consumismo diseñadas para eliminar el vínculo entre el crecimiento económico y la contaminación. ${ }^{9}$ Estos autores reconocen la capacidad de la literatura, el cine, el arte y otras manifestaciones culturales para hacer visibles las relaciones que son intencionalmente obviadas y borradas en las narrativas dominantes de la cultura de consumo y la política neoliberal. Citando a Prádanos, Amago describe el arte visual ecocrítico como «capaz de llamar la atención sobre las generalmente invisibles "conexiones entre paisajes operativos, geografías depredadoras y explotadoras, y las aglomeraciones urbanas cuasi ocultas en nuestros imaginarios cartográficos hegemónicos”». ${ }^{10}$ En el contexto del capitalismo tardío, el arte visual «ecocrítico» desarrolla una crítica de la

${ }^{6}$ Amago, S. «Waste and Space in Contemporary Spain: Photographic Archaeologies of the Anthropocene» en Arizona Journal of Hispanic Cultural Studies, n. ${ }^{\circ} 23$ (2019), p. 146.

7 Lindner, C. y Meissner, M. Global Garbage. Urban imaginaries of waste, excess and abandonment. Londres, Routledge, 2016, p. 3.

8 SAssen, S. Expulsions: Brutality and Complexity in the Global Economy. Londres, Harvard U. P., 2014, p. 90.

9 Prádanos, I. Op. cit., p. 165.

10 Amago, S. Op. cit., p. 149. Si no se indica lo contrario, todas las traducciones del inglés o el francés al español son nuestras. "Paisaje operativo» es un concepto empleado por Neil Brenner y otros investigadores asociados con el Urban Theory Lab para referirse a los paisajes tradicionalmente considerados como "periféricos» afectados por el metabolismo urbano (Brenner, N. Critique of Urbanization: Selected Essays. 2017. Disponible en: Urbantheorylab.net/new/operational-landscapes-exhibition-in-melbourne 
manera en la que se construye, fragmenta, obvia o representa el «medioambiente» en la cultura dominante - la estetización del paisaje según los intereses y usos urbanos; el refuerzo del binarismo humano/no-humano; o las representaciones que pasan por alto la existencia de ciertas especies o fenómenos-. Por supuesto, solo una fracción de las obras que representan las preocupaciones ambientalistas desarrollan una crítica de estos modos dominantes de percibir el «medio ambiente». En este sentido, solo algunos de los textos analizados en este ensayo juegan un papel «ecocrítico» a la vez que emplean la forma gráfica para subvertir la mercantilización de la vida bajo el capitalismo, criticar estereotipos idealizados de lo «verde», o representar las múltiples relaciones (espaciales y temporales) que componen los ecosistemas.

La ecocrítica y las humanidades ambientales se han desarrollado a lo largo de las últimas décadas para incluir nociones más expandidas y politizadas que a la vez son menos colonizadoras y urbanocéntricas de lo que se suele asociar con el «medio ambiente». La consolidación de la ecocrítica como un campo de estudio literario y cultural en la academia anglosajona y europea aconteció en los años ochenta y noventa. Se desarrolló al pie de los movimientos ecologistas anglosajones y europeos de los años sesenta y setenta. $\mathrm{Al}$ principio, estos movimientos se preocupaban por cuestiones concretas $\mathrm{y}$ aisladas, limitadas al ámbito local/regional, como la conservación de ciertos lugares o la mejora de las condiciones de vida en centros urbanos - así, el acceso a agua potable o la calidad del aire que empeoró por la contaminación industrial después de la Segunda Guerra Mundial-.${ }^{11}$ La publicación en 1962 del libro Primavera silenciosa de la autora y bióloga norteamericana Rachel Carson, que destacó el efecto ecológico de los pesticidas empleados en la agricultura industrial, influyó en la creación de una conciencia ecologista a una escala más amplia que se iría desarrollando en las próximas décadas. A partir de 1970, investigaciones como Los limites del crecimiento, publicada en 1972 por el club de Roma, demostraron el impacto catastrófico que estaba teniendo el metabolismo capitalista sobre los ecosistemas del planeta: es a partir de entonces cuando la crítica del metabolismo insostenible del modelo económico dominante y un mayor interés en la politización de cuestiones ecológicas a nivel global ocupan mayor espacio en los movimientos ecologistas. También influyó el movimiento antinuclear en ámbito local/regional - la resistencia a la implantación de centrales nucleares en lugares concretos - y en ámbito nacional/global — campañas a favor del desarme- . Varios estudios académicos de la época reflejaron las preocupaciones de estos primeros movimientos ecologistas, desarrollando una crítica progresista del desarrollo capitalista y el metabolismo urbano, pero fueron casos dispersos provenientes de una diversidad de campos que no se solían comunicar entre sí. ${ }^{12}$ Así también, las tradicio-

11 Rome, A. The Genius of Earth Day. New York, Hill and Wang, 2013, pp. 9-10.

12 Antes de la consolidación de la «ecocrítica» como campo de estudio (mediados de los ochenta), los trabajos académicos que analizaban las representaciones del «medioambiente» en la literatura provenían del estudio del regionalismo y el pastoralismo literario (por ejemplo, The City and the Country, de Raymond Williams en 1973). En la década de los setenta, las críticas al metabolismo capitalista también provenían de la disciplina de los estudios del campesinado (Teodor Shanin, 
nes de pensamiento provenientes de culturas no eurocéntricas han tenido una mayor influencia en la «segunda ola» ecocrítica (siglo XXI) aunque hayan mantenido una preocupación constante sobre la relación del ser humano y no humano con el entorno que habitan y hayan criticado históricamente los efectos del capitalismo. ${ }^{13}$ La primera ola de las décadas de los ochenta y los noventa se caracterizó por el análisis de la literatura ambiental (nature writing) y el empleo de nociones urbanas de «naturaleza» y wilderness que solían mantener una distancia artificial entre el ser humano y su «entorno natural», en general fuertemente estetizado. Con el paso del tiempo, la ecocrítica (de segunda ola) se ha convertido en un campo de estudio mucho más heterogéneo: por ejemplo, problematiza la separación conceptual entre los seres humanos y no humanos; estudia las relaciones del espacio urbano y la cultura de consumo; entabla debates con otras tradiciones académicas y epistemológicas como, por ejemplo, la geografía, las ciencias sociales y la ecología política, preocupándose también por la justicia ecológica y la incorporación de saberes no eurocéntricos.

\section{Trayectoria del imaginario «ecológico» del cómic español}

La trayectoria del imaginario ecológico del cómic español generalmente refleja la evolución de los movimientos ecológicos antes mencionados y las tendencias del cómic como medio, con una heterogeneidad notable que se debe, en gran parte, al legado de las políticas energéticas y desarrollistas de la dictadura - la importancia del movimiento antinuclear en los cómics de la transición- y el papel que jugó la industria de la construcción y el turismo en el crecimiento económico español desde la segunda mitad del siglo $\mathrm{xx}$ - tema recurrente en historietas y novelas gráficas en el siglo xxI- Cabe señalar una presencia significativa de perspectivas críticas con el capitalismo globalizado, aliadas con los movimientos de la alter-globalización ${ }^{14}$ y el decrecimiento, que reflejan lo que Prádanos describe como una perspectiva ecológica particularmente euro-mediterránea. ${ }^{15}$

John Berger). Otras disciplinas, como la ecología humana, la filosofía, la economía ecológica, y la historia ambiental, contribuyeron a la ecocrítica como un campo de estudio literario.

${ }^{13}$ Las constituciones de Ecuador (2008) y Bolivia (2007) incorporaron conceptos indígenas que delegan derechos a sistemas ecológicos (el concepto andino de la Pachamama, i.e. la «Tierra Madre») o proponen nociones de bienestar descolonizado (i.e., poniendo la sostenibilidad de relaciones entre seres humanos y no-humanos en el centro) (el término quechua de sumak kawsay, i.e., el «buen vivir»).

${ }^{14}$ El movimiento alter-globalización (también conocido como el movimiento anti-globalización o alter-sistema) se opone a la globalización económica del capitalismo neoliberal y propone modos alternativos para apoyar la actividad humana a escala global e imaginar valores y políticas compartidas que protejan los derechos humanos y la diversidad de las comunidades. Algunos proponentes del movimiento prefieren el uso del prefijo «alter» para distanciarse de los movimientos nacionalistas o proteccionistas que también se oponen a la globalización económica.

15 Prádanos, L. I. «Toward a Euro-Mediterranean Socioenvironmental Perspective: The Case for a Spanish Ecocriticism» en Ecozon@, n.o 4 (2) (2013), pp. 30-48. 
Revistas y cómics contraculturales de la Transición
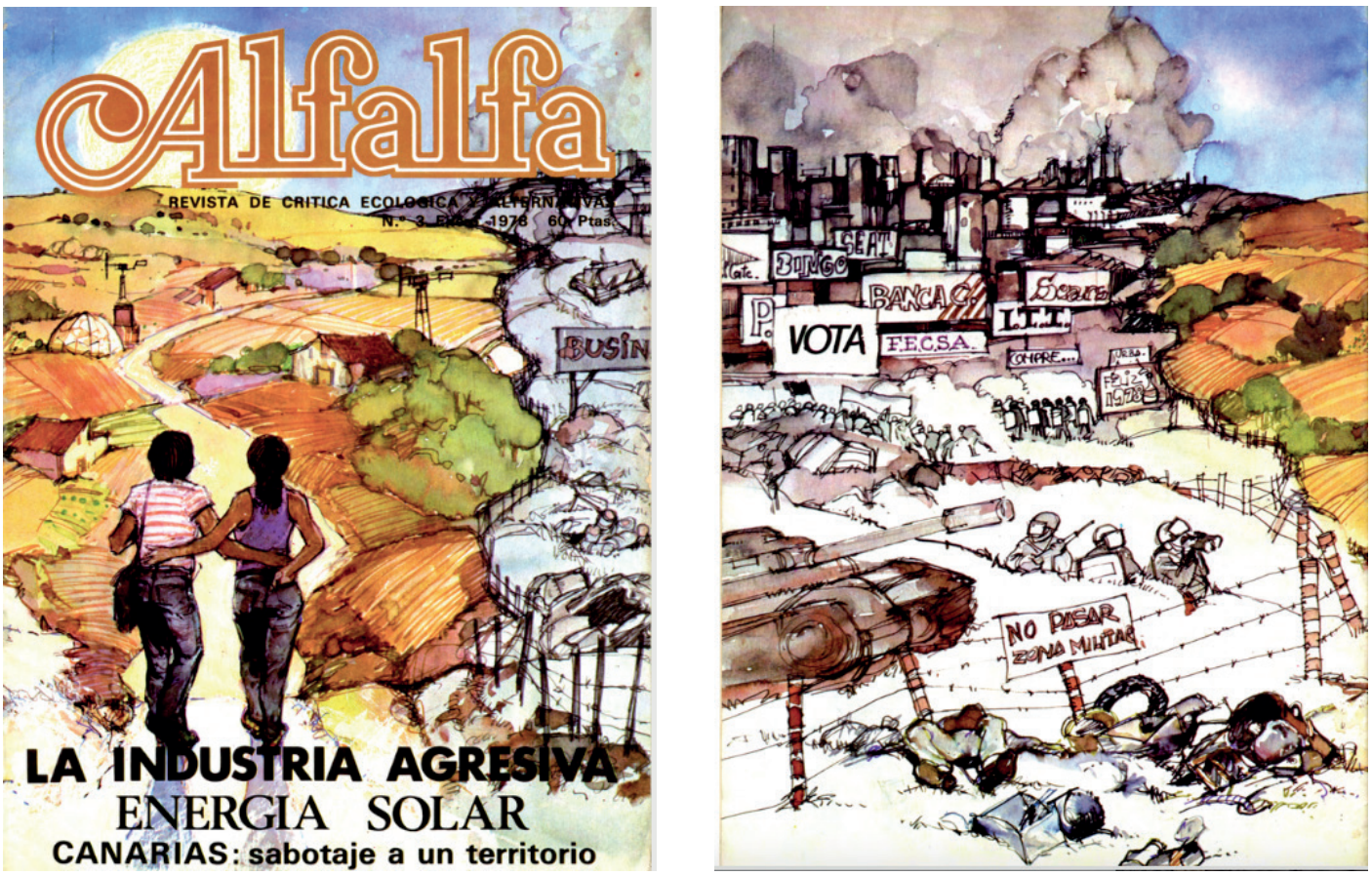

FIG. 1. Portada y contraportada. Alfalfa, n. ${ }^{\circ}$ 3, 1978.

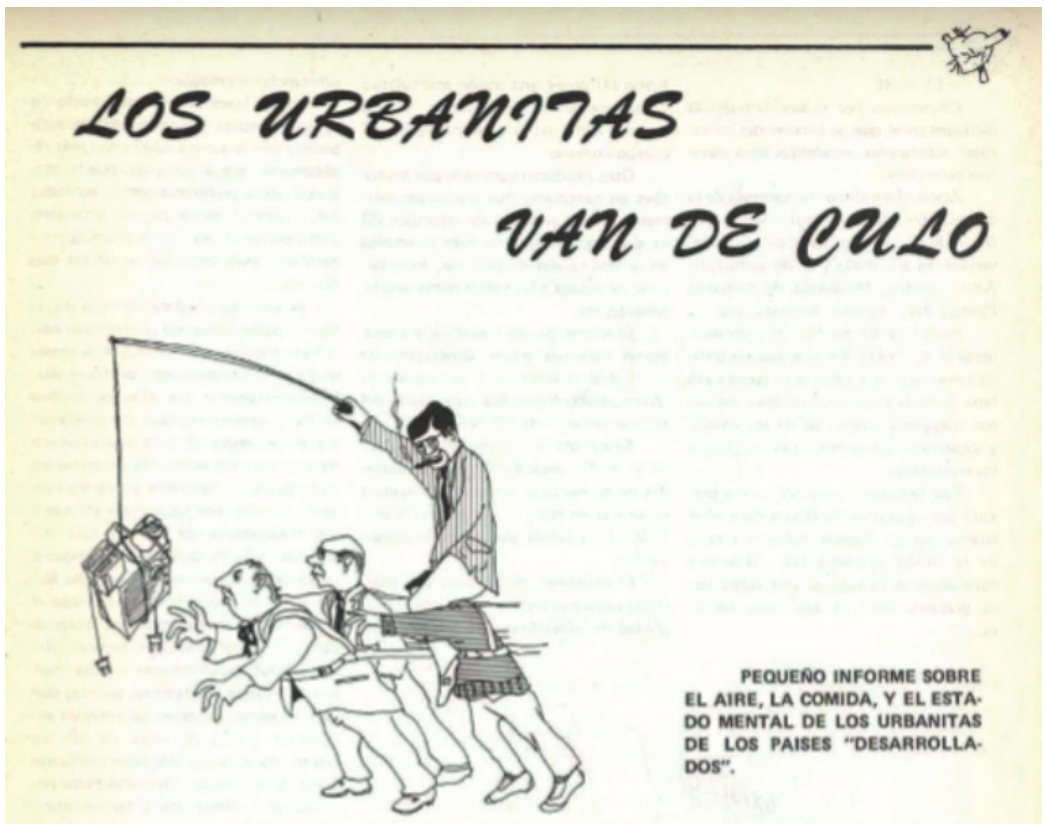

FIG. 2. El Ecologista, n. ${ }^{\circ}$ 1, 1979, p. 17. 
Los ejemplos tempranos del uso del cómic para la politización de cuestiones ecológicas están ligados a la contracultura y los movimientos sociales de los últimos años de la dictadura y de la transición - los movimientos libertarios, antimilitaristas, antinucleares, feministas y ecologistas, entre otros- Las revistas asociadas con la contracultura, el movimiento libertario, la intelectualidad comprometida o la izquierda radical — por ejemplo, Ajoblanco (1974-80), Bicicleta (1977-82), Por Favor (1974-78) y Star (1974-1980) - y las revistas explícitamente dedicadas al ecologismo radical — por ejemplo, Alfalfa (1977-78), Userda (1977-1981) y El Ecologista (1979-1993)— emplearon una gran variedad de cómics. ${ }^{16}$ Se publicaron viñetas de humor, caricaturas políticas (Alfalfa, n. ${ }^{\circ}$ 1, p. 11); viñetas que complementaban textos ensayísticos («Urbanitas van de culo», El Ecologista, n. ${ }^{\circ}$ 1, pp. 17-19); artículos de opinión gráficos («Nuestro barrio es intolerable», Ajoblanco, n. ${ }^{\circ} 16$, pp. 26-30); cómics con fines didácticos que ilustraron las energías renovables (Alfalfa, n. ${ }^{\circ} 2$, pp. 18-19) o ciclos ecológicos de contaminación radioactiva (Alfalfa, n. ${ }^{\circ}$ 2, pp. 26-27); ilustraciones gráficas de mayor elaboración para portadas y contraportadas (Alfalfa, n. ${ }^{\circ} 1$ y 3 ); y páginas enteras dedicadas a la historieta. Menos en el caso de la revista Star - dedicada por entero a la historieta-, los cómics de estas publicaciones no solo sirven para enriquecer la experiencia lectora a través del reclamo visual, sino que también desarrollan los aspectos lúdicos e imaginativos de estos movimientos, elementos fundamentales en sus propuestas políticas y estéticas -así, la capacidad de imaginar otros mundos posibles; el humor como elemento igualador; una estética del dibujo en bruto y el collage que iba en contra de las normas estéticas de la cultura elitista-. Prueba del creciente interés por la temática ecologista en el cómic durante esta época es el número especial de la revista El Ecologista titulado El Ecologista Comix (1979-1980), dedicado por entero al cómic, y un episodio del personaje Gustavo de Max, Gustavo contra la actividad del radio, publicado en 1982 en El Vibora (La Cúpula) (1979-2005), que refleja las luchas antinucleares de la época.

Por lo general, estos cómics reflejan las preocupaciones políticas, ideológicas y estéticas de los movimientos sociales y la contracultura de la época a la vez que reivindican otras formas de vida basadas en la comunidad, la auto-organización (El Ecologista, n. ${ }^{o} 1$, contraportada), la liberación sexual y la depuración del aparato estatal de toda herencia de la dictadura. Estos cómics reflejan las preocupaciones ambientales de la época - la lucha antinuclear, los planes energéticos, las crisis del petróleo- y una mayor concienciación sobre los efectos de la industria, si no a nivel planetario, sí a niveles que trascienden regiones. Por lo general, estos cómics participan de un ecologismo fundamentalmente comprometido con la transformación de la sociedad y

${ }^{16}$ Los trabajos académicos que estudian la relación entre estos movimientos sociales y las revistas de la contracultura incluyen: el capítulo de Granell Toledo, M. «Verdes, rosas y violetas: espacios políticos y nuevos movimientos sociales: la revista Ajoblanco (1974-1977)» en Rivera Blanco, A., Ortiz de Ortuño Legarda, J. M. y Ugarte Tellería, J. Movimientos sociales en la España Contemporánea, 2008; el libro de Moreno, M. y Cuevas, A. Todo era posible: revistas underground y de contracultura (1968-1983). Madrid, Libros Walden, 2020. 
la justicia ecológica que es inseparable de otras preocupaciones sociales libertarias y anticapitalistas - la violencia militar, la calidad de vida en centros urbanos, la dependencia del petróleo y el consumo de masas-. En este sentido, estos ejemplos se vinculan conceptualmente con los movimientos decrecentistas y anticapitalistas de las primeras décadas del siglo xxi. Nuestro estudio de los cómics de la transición es panorámico y se centra en revistas de fácil acceso - cabe mencionar, también, que todas provienen de Madrid o Barcelona-. Existe mucho más material que debe ser investigado, como, por ejemplo, los fanzines de la época y las revistas de menor alcance a nivel nacional provenientes de otras zonas y ciudades.

\section{Boom del cómic adulto (1970-1980)}

Durante el boom del cómic adulto los autores españoles reflexionaron, a través de la distopía, sobre un futuro lacerado por la acción del ser humano. En estos futuros dibujados, las diferencias de clase y económicas se acentúan hasta el extremo y la desintegración de las normas sociales pinta un panorama de supervivencia en el que el hombre es un lobo para el hombre. Entre las obras que ejemplifican esta tendencia están: Hombre (1981) de José Ortiz y Antonio Segura, Basura (1989) de los argentinos Carlos Trillo y Juan Giménez, publicado por Toutain en España, o las historias cortas de Auraleón publicadas en la revista 1984 en las que, desde la ciencia ficción y el género distópico, criticó la acción del ser humano en el planeta - por ejemplo, los efectos de la sobrepoblación. ${ }^{17}$

La década de los ochenta también vio la publicación de cómics de temática ecologista coordinados por organizaciones internacionales o estatales, lo cual posiblemente demuestra un interés generalizado por el medio ambiente. Estas obras incluyen $A$ mi madre la mar (título original: $\grave{A}$ ma mer), publicado por Greenpeace en Francia en 1983 y distribuido en España y en otros países en los años siguientes, con la participación de más de 75 artistas. Cabe mencionar también el cómic de catorce entregas El Pato verde (1984-1986), publicado por el Ministerio de Obras Públicas y Urbanismo - posteriormente denominado el Ministerio de Fomento- y distribuido en más de 150.000 escuelas «con la intención de difundir y vulgarizar, de manera amena y divertida, el conocimiento y la concienciación sobre los principales problemas medioambientales que afectan a la sociedad moderna y, en especial, al entorno español». ${ }^{18} \mathrm{La}$

${ }_{17}$ La sobrepoblación ha sido una cuestión muy debatida en el pensamiento decrecentista y el ecologismo social ya que puede llegar a tener resonancias ecofascistas y desviar la atención de cuestiones más importantes - la insostenibilidad fundamental del estilo de vida occidental y consumista-. Para un resumen de este debate, ver Martínez-Alier, J. «Neo-Malthusians», en D’Alisa, G. Demaria, F. y Kallis, G. (coord.) Degrowth: A Vocabulary For a New Era. Routledge, 2015, pp. 125-128.

${ }^{18}$ El Patoverde. Tebeoesfera. Disponible en: https://www.tebeosfera.com/colecciones/patoverde el 1984 mopu.html 
postura del cómic a veces resistió los planes favorecidos por otros sectores del gobierno, por ejemplo, en cuanto al turismo de costas o el Plan Almonte Marismas. En otros momentos, abordó cuestiones ambientales de modo despolitizado, elaborando ilustraciones didácticas - el ciclo del agua, las fases de una explosión nuclear- o reduciendo temas de interés público - el despilfarro de agua dulce- a una cuestión de responsabilidad individual.

\section{Los años noventa}

La dupla Antonio Segura y José Ortiz produjo en 1990 el cómic Ozono, una serie destinada al mercado italiano (L'Eternauta) pero que también se publicó en España en la revista TOTEM. Esta serie de once entregas también toma el género distópico como premisa y sitúa al lector en un futuro cercano en el que media Europa se ha convertido en una selva tropical y el norte de África en una continuación del desierto del Sahara. En este contexto, una organización internacional con sede en Roma, el Grupo de Acción Ecológica, se dedica a luchar contra cualquier tipo de delito medioambiental utilizando métodos expeditivos que no respetan los límites de la legalidad. El cómic es una sátira oscura en la que se reflejan tanto los miedos contemporáneos sobre el ambientalismo radical y el ecofascismo como las limitaciones contemporáneas al momento de imaginar alternativas socialmente deseables al statu quo del neoliberalismo dominante.

\section{El cómic desde el 2000 al 2021}

En las primeras décadas del siglo xxI se aprecia un mayor énfasis en la pedagogía y la concienciación sobre la problemática ecocrítica que a veces se traduce en un enfoque humorístico, como es la Guía para la vida del ecologista de hoy en día (2009) de Francisco Ibáñez, el prolífico autor que en esta obra retrató su particular reflexión sobre la ecología a través de sus personajes de tebeo más populares, Mortadelo y Filemón. Otras obras con un marcado carácter didáctico y divulgativo son las guías de concienciación social que integran cómic y texto informativo - como las publicadas por la Federación de Servicios y Administraciones Públicas de CC. OO.—, Cambio Climático y Sostenibilidad (2008) de Alfonso López y La Globalización. Pasen y Vean (2002) de Alfonso López y Pepe Gálvez. También debemos señalar obras financiadas por ONGs, como Puro Perú, que son un género en sí mismo con innegables aciertos - diseminación, acceso libre y concienciación- pero también limitaciones. ${ }^{19}$ Uno de los ejemplos más recientes que combinan el carácter pedagógico con un enfo-

19 No se puede dejar de señalar lo aparentemente problemático de incluir solamente dibujantes españoles para representar «la realidad» de las comunidades peruanas desde una visión ecocrítica, además de un enfoque eurocéntrico y hasta cierto punto esencialista del indígena (imagen de portada del libro) para representar un país diverso y multiétnico. 


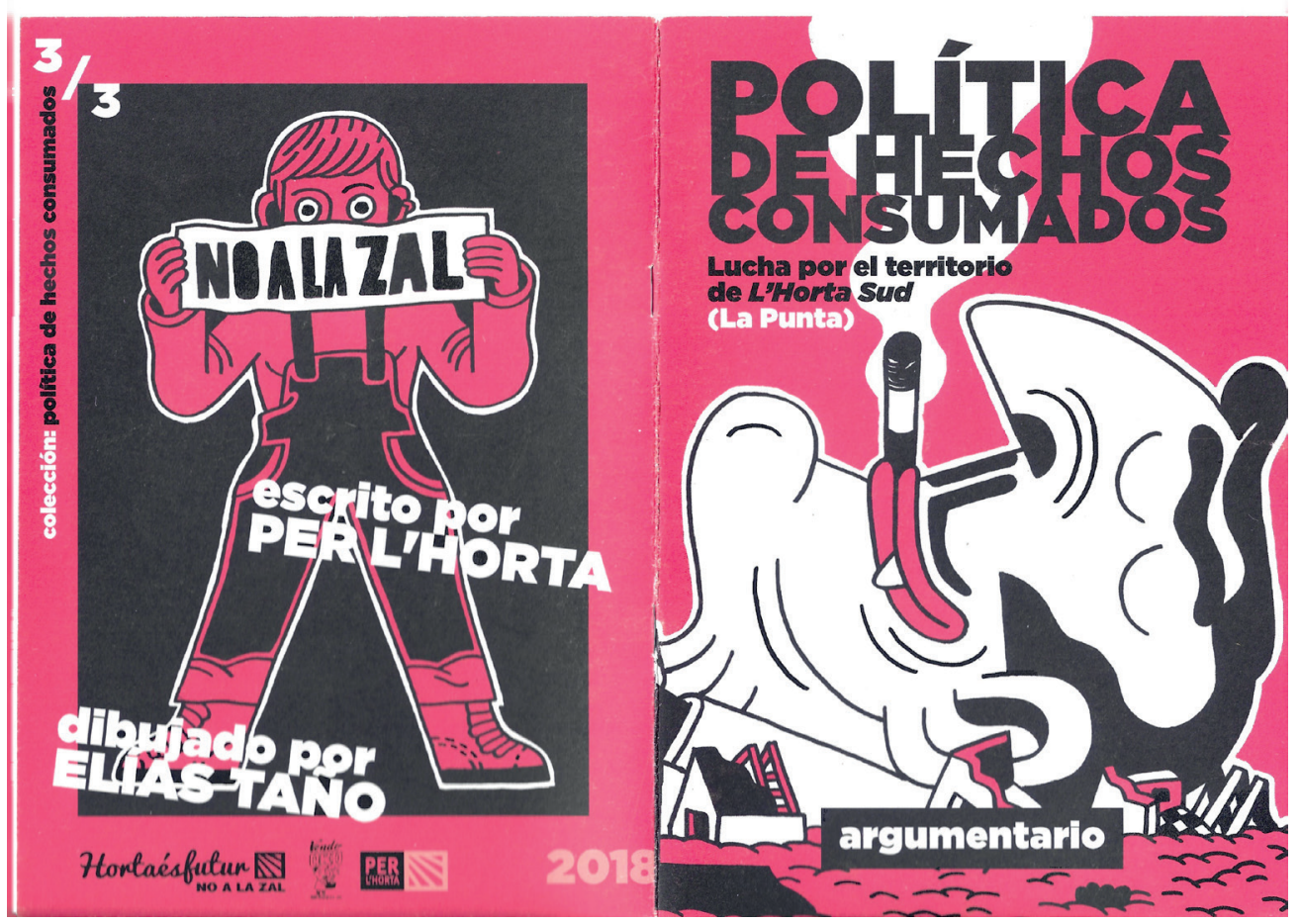

FIG. 3. Política de Hechos Consumados, n. ${ }^{\circ}$ 3, 2018, s/p.

que muy marcado en la ecocrítica es ; Vaya siglo nos espera! Instrucciones para salvar el mundo (2021) del profesor y autor de cómics Pedro Cifuentes. Este cómic, sin embargo, reproduce una retórica del «desarrollo sostenible» propia de las organizaciones históricamente responsables por las políticas injustas y ecológicamente dañinas del neocolonialismo capitalista -el Banco Mundial y las Naciones Unidas-. Finalmente, el activismo gráfico también ha denunciado los planes neoliberales que pasan por transformar zonas de alto valor ecológico y social — como es la huerta alrededor de la ciudad de Valencia- en áreas urbanizables. El caso de la Punta, en la salida sur de la ciudad de Valencia es significativo de estas luchas en las que el cómic, a través del fanzine, demuestra su capacidad de condensación de ideas e impacto visual y afectivo en el lector. Politica de Hechos Consumados. Lucha por el territorio de L'Horta Sud (La Punta) (2018) es un fanzine que publicó tres números que contaron en su n. 2 con la participación de Les Bovaes, un colectivo que trabaja la obra gráfica a través de la serigrafía, los fanzines, las máculas y la xilografía. En el n. ${ }^{\circ} 3$ participó Elías Taño, el mayor representante del activismo gráfico actualmente en España. En el n. ${ }^{\circ} 2$ se recoge que «el proyecto de la "Zona de Actividades Logísticas" (ZAL) del puerto de Valencia implicó deportar a un centenar de familias, privarlos de su forma de vida y arrasar con campos y casas para cederle al puerto un enorme solar urbanizable». ${ }^{20} \mathrm{La}$

${ }^{20}$ VV. AA. Política de Hechos Consumados. Lucha por el territorio de L'Horta Sud (La Punta). Vendo Oro, 2018. 
elección de un fanzine, un formato por excelencia libertario y no sujeto a dictados comerciales ni limitaciones industriales es, si cabe, más significativa para una mirada ecocrítica del entorno, que utiliza un soporte orgánico (el papel) para denunciar el discurso hegemónico del progreso (económico) frente a otras consideraciones como el valor social, identitario y cultural de la huerta.

Este ensayo comenzó con una breve descripción de la notable proliferación de cómics de tema ecologista publicados en las últimas dos décadas, tanto en España como internacionalmente, reflejando la exacerbación de las crisis ecológicas a nivel mundial y el creciente interés por parte de gobiernos, organizaciones, editoriales, prensa y lectores en estos temas. En la parte final de nuestro ensayo queremos compartir algunas reflexiones finales sobre las miradas ecocríticas desde la especificidad del cómic.

\section{Visiones ecocríticas desde el cómic}

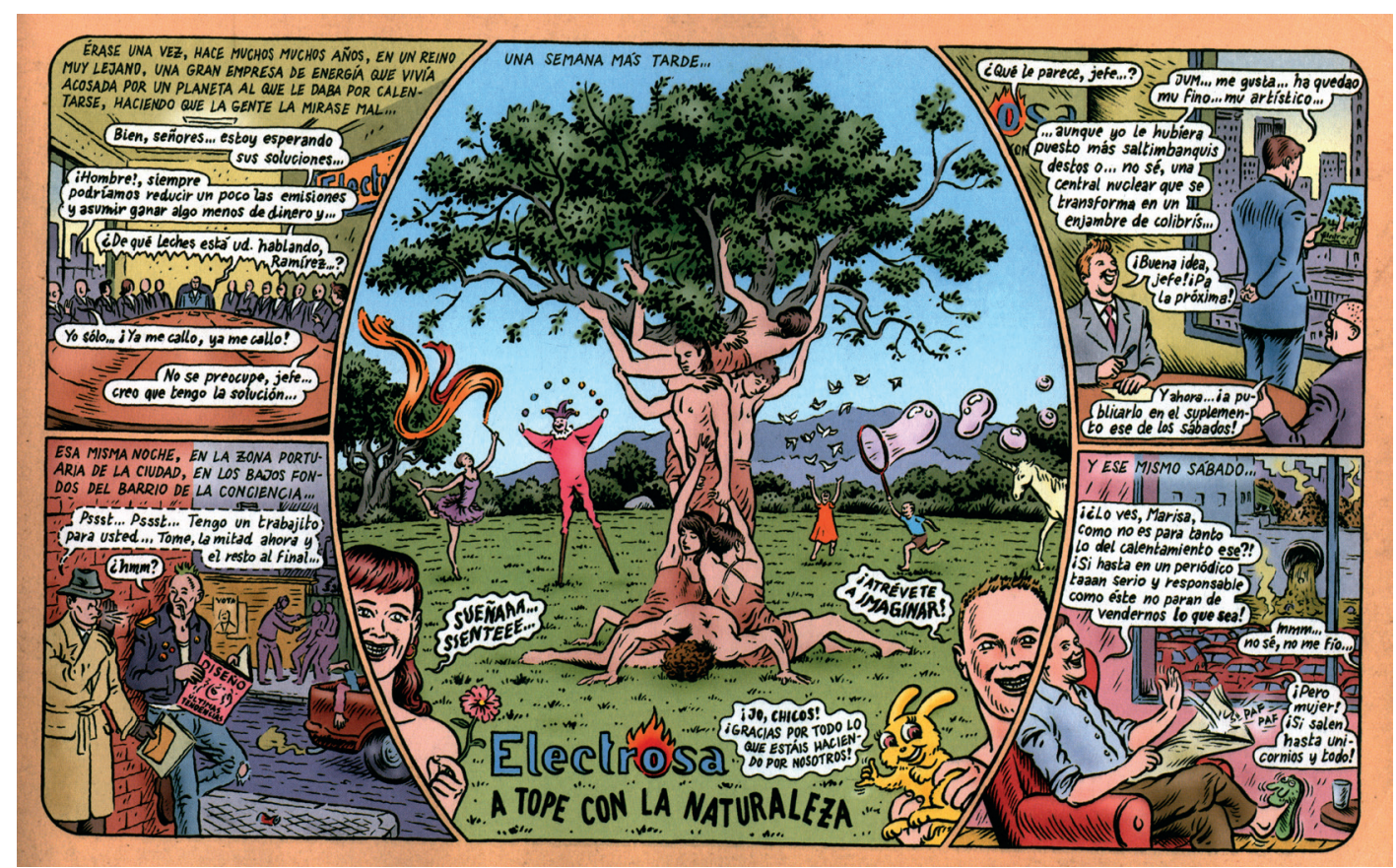

FIG. 4. BRIEva, M. «Electrosa. A tope con la naturaleza». Memorias de la tierra (85).

Más allá del estudio ecocrítico del cómic hay escasas investigaciones sobre las herramientas empleadas por los artistas para desarrollar visiones ecocríticas o «ecológicas» de la actualidad o fomentar la alfabetización ambiental. ${ }^{21}$ Los aportes del cómic en

${ }^{21}$ El «pensamiento ecológico» no se limita a formas gráficas de narración y se refiere a modos de pensar que enfatizan la interconectividad y relacionalidad de eventos, especies, y seres humanos y 
textos pedagógicos y en manuales están bien documentados y se han empleado en la enseñanza de clases de historia del arte (Pedro Cifuentes), en clases de ciencia en escuelas primarias y secundarias (las obras de Jay Hosler) o en filosofía e historia (la serie «Documentary Comic Books» publicada por Writers and Readers para estudiantes universitarios). ${ }^{22}$ De hecho, los autores y coordinadores de varios proyectos mencionados en este ensayo, por ejemplo, Puro Perú, La guerra por el agua, $;$ Vaya siglo nos espera!, El Ecologista Comix, El Pato verde, Barcelona y Memorias de la Tierra, mencionan las capacidades didácticas y narrativas del cómic en sus explicaciones de los orígenes de sus respectivos proyectos.

El cómic funciona a través de un vocabulario icónico - con una frecuente combinación de imagen y texto- aunando una aparente sencillez que puede traducirse en un dibujo llevado a la mínima expresión de la línea sobre el papel pero con una gran capacidad para desarrollos diegéticos y, sobre todo, para la metáfora - como se demuestra en las viñetas de El Roto-. Ya que el cómic está configurado por imágenes, nos parece oportuno señalar, siguiendo a Rancière, que «las imágenes del arte son operaciones que producen un distanciamiento, una desemejanza». ${ }^{23}$ Esta discrepancia que propone la imagen puede implicar dos o más maneras de acercarse a la realidad, dos o más imaginarios sociales. Y es aquí donde la especificidad del cómic, como entramado de imágenes visuales, puede condensar imaginarios alternativos que, desde una posición ecocrítica, dialoguen y resistan las narrativas neoliberales que proponen una visión teleológica del progreso sin indagar en las comunidades que son expulsadas o en las desastrosas consecuencias para el planeta.

La combinación de imagen y texto ofrece herramientas para jugar con las expectativas de la audiencia y proponer «distanciamientos» (Rancière) para cuestionar las creencias del lector. Por consiguiente, ha sido una herramienta muy útil en la subversión de formas de pensamiento arraigadas con el capitalismo y la cultura de consumo. Por ejemplo, gracias al contraste entre la imagen dibujada y el texto de las viñetas de El Roto, el artista logra cuestionar lo que se entiende por conceptos claves del imaginario dominante capitalista, como «riqueza» $\mathrm{y}$ «futuro». ${ }^{24} \mathrm{Al}$ hacer esto, el autor de cómics introduce disenso en el espacio público, al facilitar una (re)partición de lo sensi-

no-humanos a través de diferentes escalas de espacio y tiempo. Culleton, C. analiza las complejas redes que se entrelazan y diferencian las causas (no)intencionales de sus efectos (194). Martínez elabora este asunto en el contexto del cómic en «Drawing Ecological Thought» con un análisis de la obra de tres artistas de cómic españoles: El Roto, Miguel Brieva y Ramón Rodríguez.

${ }^{22}$ El lector interesado puede consultar la web Tebeosfera, que recoge múltiples trabajos. https://www. tebeosfera.com/

23 Rancière, J. El destino de las imágenes. Buenos Aires, Prometeo, 2011, p. 28.

${ }^{24}$ Martínez, C. «Drawing Ecological Thought: Anthropomorphism and Satire as Critique of Capitalism in the Twenty-first Century Spanish Comic» en Leone, M. L. y Lino, S. (eds.). Beyond Human: Decentering the Anthropocene in Spanish Ecocriticism, en preparación. 
ble que es, según propone Rancière, el conjunto de sistemas que gobiernan lo que es perceptible, pensable y posible. ${ }^{25}$ Que el cómic trate fundamentalmente de la creación de espacios y temporalidades lo convierte, en definitiva, en un medio especialmente apto para analizar el impacto de las relaciones entre los seres humanos y no humanos en el espacio que pueblan y en el tiempo que habitan.

$\mathrm{Y}$ aun siendo un medio íntimamente ligado a la cultura de consumo, los autores de cómic han empleado de manera reflexiva e irónica planteamientos formales para cuestionar la propia cultura de masas. Por ejemplo, el empleo de la retórica visual de la publicidad para la subversión de sus mensajes en el fanzine Dinero de Brieva o en las viñetas de humor publicadas en las revistas de la contracultura de la transición, o la sobria estética de las viñetas de El Roto. ${ }^{26} \mathrm{Al}$ mismo tiempo, el humor y la sátira pueden hacer que el lector esté más susceptible y abierto al mensaje crítico de fondo. Como apunta Brieva, «la letra con risa entra». ${ }^{27}$

El discurso del cómic puede representar las relaciones de interconexión que componen los ecosistemas, sobre todo aquellas que existen a través de geografías y escalas de tiempo muy expansivas. ${ }^{28} \mathrm{La}$ simultaneidad de la página del cómic - la combinación de varias imágenes y viñetas en la misma página— pone en relación diversos momentos, eventos, y elementos macro y micro. Esta relacionalidad hace posible la representación de una multiplicidad de perspectivas simultáneas: una herramienta muy útil para descentrar la perspectiva humana - ver la discusión de Sousanis en Unflattening sobre el fenómeno de «literary parallax» en el cómic, p. 45-. Aunque la narración de un cómic siga la acción de personajes humanos, a través de la simultaneidad de la imagen dibujada ciertos elementos no humanos — desechos, ecosistemas- están siempre allí, dibujados en cada panel — como en los cómics periodísticos de Sacco o en Barcelona. Los vagabundos de la chatarra- El formato gráfico of rece varias posibilidades para narrar la subjetividad, el sufrimiento, y la experiencia del ser no-humano. ${ }^{29} \mathrm{La}$ imagen dibujada también permite la imaginación y representación visual de temporalidades y elementos demasiado grandes o pequeños para el ojo humano que son inasequibles a otras formas de representación visual — como la fotografía-. Por esta razón, el cómic ha jugado un papel importante en la imaginación visual de otros

${ }^{25}$ Rancière, J. The Politics of Aesthetics: The Distribution of the Sensible. Londres, Continuum, 2004, p. 12.

${ }^{26}$ Mate argumenta al analizar la estética austera de las viñetas de E1 Roto, que «en un mundo visualmente saturado, la eficiencia rima con la sobriedad» (p. 12).

27 Brieva, M. «El secuestro de la imaginación como freno crucial al cambio social». ALCES XXI, n. ${ }^{\circ}$ 1 (2013), pp. 339-341.

${ }^{28}$ Martínez, C. Op. cit.

${ }^{29}$ Para profundizar más sobre la representación de subjetividades no-humanas en el cómic, se puede consultar Martínez, C. Op. cit. y Yezbick «Lions and Tigers and Fears: A Natural History of the Sequential Animal» en Herman, D. Animal Comics: Multispecies Storyworlds in Graphic Narratives, Londres, Bloomsbury Academic, 2017, pp. 29-52. 
futuros o realidades posibles - ya sea en los géneros de la ciencia ficción y la fantasía o en la ilustración de futuros utópicos/distópicos.

Al emplear las técnicas antes mencionadas, algunos artistas han desarrollado su propia «ecocrítica» de la política, la cultura y la economía dominante y de su manera de definir y fragmentar las relaciones ecológicas — por ejemplo, el lenguaje «verde», naturalista- Artistas como Brieva y E1 Roto emplean las herramientas del cómic para criticar los tópicos y simplismos del capitalismo verde y su cooptación del interés popular por el medioambiente (FIG. 4), descentralizar la perspectiva humana, y - según la función del arte visual ecocrítico antes mencionado- llamar la atención sobre las generalmente invisibles «conexiones entre paisajes de explotación, geografías depredadoras y explotadoras, y las aglomeraciones urbanas cuasi ocultas en nuestros imaginarios cartográficos hegemónicos». ${ }^{30}$ En la figura 4 Brieva parodia la iconografía «verde» empleada por las corporaciones —el árbol, el color verde, flores y mariposas y otros seres no humanos que se consideran agradables dentro de las jerarquías de la naturaleza estetizada de la sociedad moderna-. Con el uso de la imagen gráfica y la simultaneidad de múltiples viñetas en la misma página, Brieva pone esta iconografía dentro de una ecología de relaciones imaginadas que hace perceptibles las prácticas y consecuencias socioambientales invisibilizadas por el greenwashing. Esta ficción dibujada también sirve para animar al lector a juzgar las corporaciones no por su publicidad sino por el impacto socioambiental de las prácticas que la misma corporación se esfuerza en que pasen desapercibidas. ${ }^{31}$

Para concluir, quisiéramos animar a lectores e investigadores ya que la cantidad de obras que emplean las herramientas específicas del cómic para intervenir en las crisis socioambientales actuales es enorme y la mayor parte de estas obras está por analizar y estudiar. Creemos que es un terreno fértil para examinar las limitaciones, contradicciones, historias y aportes de artistas y movimientos que abogan por la transformación de la sociedad actual y por alternativas a la sociedad capitalista y consumista.

30 Prádanos. L. I. Op cit., p. 35.

${ }^{31}$ Martínez, C. «The Affirmative Politics of Degrowth: Miguel Brieva’s Graphic Narrative Memorias de la Tierra» en Journal of Spanish Cultural Studies, n. ${ }^{\circ} 18$ (2), 2017, pp. 201-202. 


\section{Bibliografía}

Amago, S. «Waste and Space in Contemporary Spain: Photographic Archaeologies of the Anthropocene». Arizona Journal of Hispanic Cultural Studies, n. ${ }^{\circ} 23$ (2019), pp. 146-166.

Beilin, K. «Coda 1: Blind Spots, Financialization and Cucumbers». Arizona Journal of Hispanic Cultural Studies, n. 23 (2019), pp. 243-252.

Brieva, M. Memorias de la Tierra. Barcelona, Random House Mondadori, 2012.

— «El secuestro de la imaginación como freno crucial al cambio social». ALCES $X X I$, n. ${ }^{\circ} 1$ (2013), pp. 297-353.

Catalá-Carrasco, J. L. «Neoliberal Expulsions, Crisis, and Graphic Reportage in Spanish Comics». Romance Quarterly, n. 64 (4) (2017), pp. 172-184.

Culleton, C. P. «The Force of Nature: Learning to Think Ecologically from Rúben Abella's El libro del amor esquivo». Letras Hispanas, n. ${ }^{\circ} 13$ (2017), pp. 194-206.

Dobrin, S. I., \&Weisser, Christian R., (eds.).Ecocomposition. Albany, SUNY,2001.

Glotfelty, C. «Introduction» en Glotfelty, C. y Fromm, H. (eds.). The Ecocriticism Reader: Landmarks in Literary Ecology, pp. xv-xxxxviii. Athens, Georgia U.P, 1996.

Lindner, C. y Meissner, M. (eds.). Global Garbage. Urban imaginaries of waste, excess and abandonment. Londres, Routledge, 2016.

Martínez, C. M. «The Affirmative Politics of Degrowth: Miguel Brieva's Graphic Narrative Memorias de la Tierra». Journal of Spanish Cultural Studies, n. ${ }^{\circ} 18$ (2) (2017), pp. 191-212.

— «Urban Ecology and Comics Journalism in Jorge Carrión and Sagar Forniés's Barcelona: Los vagabundos de la chatarra (2015)» en Amago, S. y MARr, M. (eds.). Consequential Art: Comics Culture in Contemporary Spain, Londres, University of Toronto Press, 2019, pp. 164-191.

- «Drawing Ecological Thought: Anthropomorphism and Satire as Critique of Capitalism in the Twenty-first Century Spanish Comic» en Leone, M. L. y Lino, S. (eds.). Beyond Human: Decentering the Anthropocene in Spanish Ecocriticism. [En prensa]. 
-Living Finitude in an Age of Growth: Spanish Late Capitalism and its Discontents [tesis doctoral]. New York University, 2021.

Mate, R. «E1 Roto, Au Secours d'une Réalité Occultée», en Le Cabier Électrique. Les Cahiers Dessinés (2012), pp. 7-17.

Prádanos, L. I. «Toward a Euro-Mediterranean Socioenvironmental Perspective: The Case for a Spanish Ecocriticism».Ecozon@, n.o 4 (2) (2013), pp. 30-48.

-Postgrowth Imaginaries. New Ecologies and Counterhegemonic Culture in Post2008 Spain. Liverpool, Liverpool U.P., 2018.

— «Energy Humanities and Spanish Urban Cultural Studies: A Call for a Radical Convergence», en Beilin, K., Conolly, K. y McKay, M. (eds.). Environmental Cultural Studies Through Time: The Luso-Hispanic World, Hispanic Issues On Line, n. ${ }^{\circ}$ 24 (2019), pp. 27-45.

Rancière, J. The Politics of Aesthetics: The Distribution of the Sensible. Londres, Continuum, 2004.

—El destino de las imágenes. Buenos Aires, Prometeo, 2011.

Rome, A. The Genius of Earth Day. New York, Hill and Wang, 2013.

Saltzman, M. Everyday Agency in the Discarded: Cultural Politics in the Public Spaces of Neoliberal Barcelona. [En prensa].

Sassen, S. Expulsions: Brutality and Complexity in the Global Economy. Londres, Harvard U.P., 2014.

Sousanis, N. Unflattening. Londres, Harvard U.P., 2015.

VV. AA. Politica de Hechos Consumados. Lucha por el territorio de L'Horta Sud (La Punta). Vendo Oro, 2018. 